\title{
Leadership Behavior Analysis: The Case of Three Academic Middle-Level Leaders in Higher Education
}

\author{
Mohammed Issah \\ Department of Education Studies, Bahrain Teachers College, University of Bahrain, Zallaq, The Kingdom of Bahrain \\ Email: missah@uob.edu.bh
}

How to cite this paper: Issah, M. (2020). Leadership Behavior Analysis: The Case of Three Academic Middle-Level Leaders in Higher Education. Open Journal of Leadership, 9, 141-155.

https://doi.org/10.4236/oj1.2020.93009

Received: July 11, 2020

Accepted: August 21, 2020

Published: August 24, 2020

Copyright $\odot 2020$ by author(s) and Scientific Research Publishing Inc. This work is licensed under the Creative Commons Attribution International License (CC BY 4.0).

http://creativecommons.org/licenses/by/4.0/

\begin{abstract}
This study explored leadership behavior and practices of three academic program heads in higher education. The paper discusses the responses of three academic leaders in higher education institutions within the framework of adult learning, drawing specifically from adult learning theories including andragogy, transformation learning, experiential learning, and cognitive learning. The study employed a qualitative approach, using semi-structured interview format and observation in gathering data on the behavior of the leader. The academic program heads in a Mid-Western university in the United States of America responded to questions and their responses analyzed with a framework of selected adult learning theories. The data were analyzed using thematic analysis and five themes emerged. The thematic analysis revealed five themes; 1) reflection/learning from experiences 2) coping with stress 3) feedback 4) linking relationships, positive environment, and achieving objectives 5) tangible outcomes as success/rewards of leadership. Also, the analysis reveals elements of transformational learning in the leaders' practices. The paper concludes with implications for leadership development in higher education. The study focused on the behavior of three academic program heads in a single university and the findings are not generalizable. In addition to other leadership competencies, leaders should be equipped with emotional intelligence. The study highlights the interconnectedness of leader behavior and adult learning theories, an area that has little attention in research on leadership in higher education.
\end{abstract}

\section{Keywords}

Leader Behavior, Higher Education, Adult Learning Theories, Academic Leader, Leadership Development, Academic Leaders 


\section{Introduction}

Leadership is a complex set of behavior as alluded to in numerous studies on the concept (Curnow, Mulvaney, Calderon, Weingart, Nicely, Keller-Glaze, \& Fallesen, 2006), and leadership development is a process that individuals and or leaders go through, and in this process, they acquire the experience and requisite skills in leading others (Hoppe, 2007). Kakabadse and Kakabadse (2009) posit that leadership is a developmental process based on the choices a leader makes. The choices according to the authors are made per the perspective of the leader. There is an increasing demand for research in leadership in higher education settings because leaders in academic settings play essential roles in the development and support of alliances with higher educational and social institutions to meet the demands and requirements of society (Hamidifar \& Ebrahimi, 2016). "Individuals with formal leadership responsibilities in higher education have significant influence over the culture and the power to determine how teaching workloads are distributed, adjusted, and rewarded” (Hofmeyer, Sheingold, Klopper, \& Warland, 2015: p. 187). "Leaders need a set of tools to accomplish their work, including communication skills, an effective leadership style, and emotional intelligence" (Freed, 2016: p. 7). In furtherance, Sahgal and Pathak (2007) emphasized that in addition to leading and inspiring others, life experiences play a significant role in building the capabilities of individuals to achieve professional success. Previous studies provide evidence to suggest that the learning habits of leaders impact their behavior, practices, and influence, and the subsequent impact at the individual and organizational levels (see Argyris, 1991; Johnson, 2002; Senge, 1990).

I was interested in the leadership behavior and practices of academic leaders in higher education, and what adult learning theories explain the leaders' behavior. In other words, explore the connection between adult learning and leadership behavior and practices in academic leadership. Besides, I was interested in determining the level of leadership development of the academic heads of programs in higher education. Despite the extensive literature on leadership, writers and researchers on leadership have noted the more limited investigations and understanding of leadership within higher education (Bryman \& Lilley, 2009; Middlehurst, Goreham, \& Woodfiled, 2009), and more specifically little is known of the connection between adult learning and leadership behavior and practices.

The purpose of this study is to explore the leadership development of three leaders of educational programs in a higher educational institution, and possible links to adult learning theories. Heads of programs in higher education are among the staff described as academic leaders. These leaders by their positions give far more focus on working directly with students, program development, and implementation than other leadership roles (Scott, Coates, \& Anderson, 2008: p. xvi). Specifically, the study examined the behavior of the three leaders based on their responses during the interview and determined the adult learning 
theory elements the leaders incorporate in their practices. The following questions were addressed in this study.

Research Question: To what extent do the leaders of educational programs incorporate adult development theory into their leadership practices?

\section{Sub-questions:}

Which model(s) of adult learning explains leader responses?

What elements of transformational learning are evident in leader responses?

Which Leadership Development Level does each leader reflect?

This paper presents an introduction to the research, literature review on adult learning theories, the methodological approach adopted in the research. The methodology section includes profiles of the interviewees, the analysis and discussion of interview responses. Finally, the implications of the research and conclusion presented.

\section{Adult Learning Theory-Andragogy}

Adult learners are different from other learners because of their distinctive and desired outcomes of learning (Stevens, 2014). "Adult learning theory is an important factor in leadership development" (Allen, 2007: p. 26). According to Allen (2007) adult learning is a personal process. "Adult learning is defined as the process of adults gaining knowledge and expertise based on their personal goals” (Knowles, Holton III, \& Swanson, 2005: p. 173). Adult learning is described as self-directed, experiential in nature, voluntary, collaborative, participatory, and transformative (Knowles, Holton III, \& Swanson, 2005; Mezirow, 1997). In simple terms, adult learning is a change in behavior (Merriam, Caffarella, \& Baumgartner, 2007). Adult learning, according to Morris and Klunk (2016), addresses adult development within the context of changes in capabilities, perspectives, and worldviews as one goes through life. Adults learn about themselves and form their experiences when given the opportunity to engage ones' cognitive capacity in challenging situations, as a result make better choices in the future (Lapina, 2018).

In 1968 Malcolm Knowles proposed the concept of andragogy, which is "the art and science of helping adults learn" (Knowles, 1970: p. 38). Andragogy is viewed predominantly as the theory of adult learning (Merriam et al., 2007). Malcolm Knowles identified five key underlining assumptions of andragogy that describes an adult learner as someone who 1) has an independent self-concept and who can direct his or her learning 2) has accumulated a reservoir of life experiences that is a rich resource for learning, 3) has learning needs closely related to changing social roles, 4) is problem-centered and interested in immediate application of knowledge, and 5) is motivated to learn (Knowles, Holton III, \& Swanson, 2005: p. 3). Despite the lack of direct examination of the impact of learning theories and leadership, as Curnow et al. (2006) noted, theories such as transformational learning, experiential learning, and cognitive flexibility seem applicable to leadership development. Before 1968 Lindeman noted that central 
to adult learning is the learners' life experiences, and that some conditions must be met before they choose to learn. Thus, Linderman made five key assumptions about adult learners; 1) Adults are motivated to learn as they experience needs and interests that learning will satisfy, 2) Adults' orientation to learning is self-centered, 3) Experience is the richest source for adult's learning, 4) Adults have a deep need to be self-directing, 5) Individual differences among people increase with age (Knowles et al., 2005: p. 40). Similarly, Madsen, O’Mullan, and Keen-Dyer (2014) outlined participation; respect; collaboration; praxis; critical reflection; and self-direction as the six principles that underpin adult learning.

\subsection{Transformational Learning}

Transformational learning is described "as the essence of adult education" (Mezirow, 1997: p. 11). Transformative learning occurs when individuals critically reflect upon their environment and learning, and through the critical reflection, these individuals modify their frame of reference and view of the world (Allen, 2007). Critical reflection, according to Reardon, Fite, Boone, and Sullivan (2019) is a skill set that facilitates an adult re-examining his or her basic beliefs to improve understanding. Transformational and self-directed learning requires the learner to draw upon their prior knowledge and experiences and to reflect upon their motivations for learning (Cale, 2017). Reardon et al. (2019) further contend that without critical reflection, professionals act either as they are taught or act based on experience. For example, in the study of the middle-level managers in Australian Higher Education, Vilkinas (2014) concluded that introspection and self-awareness provided the middle managers with opportunities to learn from their previous experiences and to inform future behaviors.

Transformational learning accounts for societal influence on learning and construction of knowledge, and the individuals' learning results from the interaction and reinforcement of others' behavior (Sharma, 2013). Core to transformational learning is the idea that adults make meaning of their experiences and generate their perspective (Allen, 2007; Sharma, 2013). According to Sharma (2013), the perspective generated is only altered by a new experience resulting in learning and development of a new perspective. Thus, learning occurs as leaders shift their framing and can lead to more change in perspective and world view (Allen, 2007). For instance, Goleman (2004) asserts that "self-awareness is the ability to understand one's modes, emotions, and drives as well as its effects on others" (p. 4). Also, "transformational learning can provide a sense of self-efficacy that re-positions adults for a brighter future" (Foote, 2015: p. 85). "Adult learning is about the development of independent thinking which aligns with the objectives of many leadership development programs" (Allen, 2007: p. 33). Despite, the popularity of Mezirow's transformational learning theory, it has been critiqued for its focus on the cognitive process involving critical reflection and discussion, with no attention to context and culture (Baumgartner, 2001; Merriam, 2001). 


\subsection{Experiential Learning}

Closely related to transformational learning is experiential learning. The experiential theory was proposed by Kolb (1984), which is that "learning, change, and growth occur when learners reflect on their experience". Kolb (1984) proposed a cycle of experiential learning comprised of four elements: concrete experience, reflective observation, abstract conceptualization, and active experimentation. Besides, Kolb (1984) summarized six prepositions regarding experiential learning 1) learning is a process, not outcomes 2) All learning is relearning 3) learning requires the resolution of conflicts learning results from a synergistic transaction between a person and the environment 4) Learning is the process of creating knowledge not transmitting knowledge.

\subsection{Cognitive Learning}

The cognitive learning model focuses on the internal aspects of learning (Allen, 2007). It is based on the assumption that optimal learning occurs when information is logically presented in a pre-planned sequence of modules, where the information is assimilated into the learner's pre-existing mental framework ( $\mathrm{Wu}$ estewald, 2016). Cognitive learning is characterized by an organized, linear progression of subject matter leading to a mastery of a body of knowledge (Merriam et al., 2007). Proponents of the cognitive learning model "view people as part of their environment, having the potential to influence the environment around them" (Allen, 2007: p. 29).

\section{Methodological Approach}

The study adopted a qualitative approach with a case study design. This approach is most suitable because it is "open-ended" and allows for an "in-depth" exploration of the issue (Mertler, 2019: p. 94). The interview was conducted in a semi-structured format. The semi-structured format was necessary to allow the researcher to seek clarifications to the responses of the leaders. Although the analysis involves comparing leader response, "consistency is usually not a concern when collecting qualitative data because it is typically more desirable for the researcher to have some flexibility and to be able to ask clarifying questions, to pursue information not initially planned for, and to seek different information from different people" (Mertler, 2019: p. 131). Three academic leaders within the middle management of a university in the mid-western United States were contacted to participate in the study and all three consented. All three participants were heads of programs at the time of the interview. These leaders by their positions give far more focus on working directly with students, program development, and implementation than other leadership roles (Scott, Coates, \& Anderson, 2008: p. xvi). The interview was conducted in the respective offices of the leaders. Additional notes were taken about the office environment of all three leaders. Each of the interviews lasted approximately 45 to 60 minutes. To collect the data, 12 questions were formulated to guide discussions with the leaders. 
Thematic analysis of the data collected revealed five underlying themes: 1) reflection/learning from experiences 2) coping with stress 3 ) feedback 4) linking relationships, positive environment, and achieving objectives 5) tangible outcomes as success/rewards of leadership.

\section{Profiles of Interviewees}

Leader L1: Leader L1 is 64 years old. He is the Director of a program in a higher education institution. Until he was appointed the Director, he worked as an instructor for six years, a position he loved so much because of the frequent interaction with students in the program. Leader L1 is a college graduate. At the time of the interview, Leader L1 was in his sixth year as Director of the program, a position at which he intends to retire.

Leader L2: Leader L2 is in his mid-fifties. Leader L2 is the Director of a program in a higher education institution and a professor in humanities. He has been in that position for 11 months. Before this position, he had no prior administrative experience in higher education. He holds a Ph. D in Geography. He supports and mentor leaders of student organizations.

Leader L3: Leader L3 is in her late fifties. She is a Coordinator of a program in a higher education institution, a position she held for four years at the time of the interview. Also, she is a professor. She has a Bachelor's in English, a secondary education certificate, a Master of Arts in international studies, and a Ph.D. in Education (Educational Psychology \& Comparative Education).

\section{Analysis and Discussion of Leader Behavior}

Three middle-level academic leaders were interviewed, and five themes emerged from the thematic analysis. These include 1) reflection/learning from experiences 2) coping with stress 3) feedback 4) linking relationships, positive environment, and achieving objectives 5) tangible outcomes as success/rewards of leadership. All five themes reflect elements of transformational learning, and experiential learning (See Kolb, 1984; Allen, 2007; Mezirow, 1997; Baumgartner, 2001; Merriam, 2001).

Learning from experience: leaders must value learning (Bennis, 1984), and responsible for their learning (Senge, 1990). From the responses of three leaders, it is evident they learned from their experiences along the way as they assumed leadership positions. The leaders rely on their experiences as valid data to critically reflect on their behavior, thought process in action, and so learn more deeply about themselves. According to Reardon et al. (2019), the reflective analysis of the leader is intended to contribute to improving individual growth and improvement. Also, the leaders did indicate that they observed other leaders they regarded as effective leaders. Learning from both the successes and mistakes of such leaders, although none of the three leaders identified the leaders from whom they learned. According to Knowles's theory of andragogy and Jarvis's learning process, the experience is a rich source for adult learning (Merriam et 
al., 2007). Similarly, in Illeris's three dimensions of learning model, experiences are identified as one of the five stimuli of the learning process (Merriam et al., 2007).

Furthermore, the three leaders learned from their experiences because, according to Jarvis's model of the learning process, the leaders re-examine the underlining assumptions, values, attitudes, and beliefs concerning their actions (Merriam et al., 2007). The reflective learning process, according to Mezirow (1997) is transformational learning because it enables the leaders to make meaning of their experiences to guide future actions (Merriam et al., 2007). To develop, it is integral for the leaders to learn to reflect-in-action and adapt their behaviors to the situation (Reardon, Fite, Boone, and Sullivan, 2019: p. 30). According to the Integrated Competing Values Framework, leaders who learn from their experiences, change their behavior after reflecting, and respond to others and situations appropriately by being critical observers and reflective learners (Vilkinas, 2014). Critical reflection on experience is an essential skill in effective leadership development (Reardon et al., 2019).

\subsection{Coping with Stress}

With regards to coping with stress, interestingly all three leaders revealed that they make conscious efforts to delegate tasks to coworkers better equipped with skills to accomplish the task, and so doing reduce the level of stress they experience. Also, Leader L1 and Leader L2 mentioned prioritizing their tasks to reduce the stress associated with their work. McClusky's theory of margin can explain the stress experienced by the leaders (Merriam et al., 2007). Furthermore, situations that stretch and remove leaders from their comfort zone, presents important learning opportunities to guide future actions.

However, there were differences in the level of stress experienced by all three leaders. All the leaders experience stress from the work they do but they each have a different way of coping with the stress. Differences in stress levels among all three leaders were evident in their responses. Leader L1 seemed to experience stress more than the other two leaders, and Leader L2 seemed the least stressed. According to Leader L1, he is usually stressed by the volume of work that needs to be accomplished on any given day. He said he often takes on too many tasks which sometimes lead to ineffectiveness. This was similar to Leader L3's response to stress. However, a closer look at the office environment gives a different impression. For instance, of the three leaders, Leader L3's physical office space was more organized while that of Leader L1 and Leader L2 looked disorganized with piles of materials sitting on their desks and the floor. Again, unlike the other two leaders, Leader L2 purposefully chose the location of his office which serves as an alternate route in and out of the classroom. "I grasp onto the opportunity to interact with the students as they walk through my office” (L2).

\subsection{Feedback}

All three leaders were quite open to receiving feedback, and they specifically said 
they received formal feedback from higher administrative positions according to the chain of command of the university. Feedback for leadership is the process of critical reflection on the leader's styles and practices (Reardon et al., 2019). Informally, they receive feedback from students and colleagues in their respective programs. According to the three leaders, the formal feedback takes the form of annual assessments, peer review, and occasionally at program level meetings.

\subsection{Building Relationship}

All three leaders stressed the importance of relationship-building to achieve organizational goals and objectives. Each of the leaders takes opportunities for both formal and informal social events to build relationships with the people they work with. The role of relationship in the transformational learning process has been acknowledged, although it remains as one of the unresolved issues in Mezirow's theory of transformative learning (Merriam et al., 2007). The relationship established between the leaders and the follows is an important aspect of leadership common across various leadership models (Reardon et al., 2019). For example, in the five exemplary practices of leadership, motivation is provided by the interaction between the leader and the followers (Kouzes \& Posner, 2006). Therefore, the inability of leaders to maintain relationships can be harmful to their efforts at leading others (Albert, undated).

Although all three leaders said they build relationships as part of creating a positive work environment, there were slight differences in other things they do to create such an environment. As Leader L1 indicated, having confidence and trust in coworkers to carry out their responsibilities without necessarily having to remind them creates a positive work environment (Reardon et al., 2019). Besides, leaders need to be outward-looking and have institutional credibility to create positive work environments for staff (Hofmeyer et al., 2015).

In other words, allowing people the freedom to do their work without micro-managing them improves the relationship between the leader and those he works with. For Leader L2, he believes that treating people the way one will like to be treated helps to create a positive work environment. However, Leader L3 ensures that she gives opportunities to other members of her grant projects. She referred to a recent incident where she invited a newly recruited member of faculty to participate in her project. She uses this approach to create an environment where members collaborate. Of the three leaders, Leader L3 was the leader who lamented about ideas she could implement to further promote a positive environment but unable to do that because of the limited authority boundary.

\subsection{Tangible Outcomes}

Again, all three leaders' made reference to tangible outcomes, and belief in achieving organizational objectives and goals. They referred to tangible outcomes and continuous improvement as success/rewards of leadership. This 
theme is a key concept in transformational learning (Merriam et al., 2007). Furthermore, the view of the three leaders interviewed on achieving tangible outcomes such as organizational goals and outcomes, as a measure of success, rewards, and growth are practices common to various leadership models (Reardon et al., 2019), and any leadership model that ignores these aspects of leadership as motivators is incomplete (Reardon et al., 2019).

On the issue of primary influence, it was interesting to note that all three leaders did not mention particular individuals who influenced their leadership, even though they acknowledged observing leaders they thought were effective. They felt strongly about developing as leaders through their experiences. For instance, Leader L1 said, "I grew up with a sense of responsibility". By being responsible he established and managed his business for several years. Leader L3 said, "I model my leadership style". She believes in leading within the framework of democratic principles. Although all three leaders make the final decisions at their level, they each vary in the extent to which they employ participatory decision making. Unlike Leader L1 and Leader L2 who mostly apply university guidelines in decision making, Leader L3 on the other hand applies participatory approaches during discussions and making decisions. Leader L3 referred to an instance where a senior member was of the view that junior members did not matter on a particular issue and therefore need not be involved in making the decision. According to Leader L3, she disagreed with the senior member and ensured that both senior and junior staff participated in making the decision. Thus, it sounds to reason that what leaders do is largely dependent upon the characteristics of the situation in which they function (Arntzen, 2016).

\subsection{Which Model(s) of Adult Learning Best Explains Leader Behavior?}

Knowles's theory of andragogy. The focus of this theory is the individual and his or her life situation. The underlying assumptions of this theory are, adult learning is self-directed, learning from experience, problem-centered, internal motivation, and rationale for learning. The responses from all three leaders indicate that they learned from their experiences as well as from others, and made adjustments in their leadership over time.

Jarvis model also explains the responses of the three leaders interviewed. According to the model, adult experiences serve as the beginning of the learning process. Learning is initiated when people find themselves in an unfamiliar situation that cannot be automatically understood or deciphered (Merriam et al., 2007). All three leaders indicated that they learned from their experiences and also observed other leaders they thought were effective leaders. Although there were no specific examples, Leader L1 referred to learning a lot about his leadership over the period he managed his private business. His experience as an entrepreneur impacted positively on his leadership development. The ability of the leader to learn from experience, according to Van Velsor and Guthrie (1998) is essential in "responding to change quickly and to effectively handle situations" 
that are not so obvious. More importantly, the ability of a leader to learn from experience can be effective since leaders cannot always wait on "others to instruct them how to proceed" (Curnow et al., 2006: p. 46). As noted by Kolb (1984), in his proposed experiential learning, learning, change, and growth occurs when learners reflect on their experience.

McClusky's theory of margin. According to the theory of margin, adult life is the load that adult carries in living and the power that is available to him or her to carry the load. It is grounded in the notion that adulthood is a time of growth, change, and integration in which one seeks a balance between the amount of energy needed and the amount available (Merriam et al., 2007: p. 93). This theory explains the seemingly different stress levels found among the leaders about workloads associated with their jobs. This theory best explains the varying stress levels found among the three leaders. As Lapina (2018) noted, the type of coping strategy adapted impacts the learning outcomes, stress levels, and adults' experience with learning.

\subsection{What Elements of Transformational Learning Are Evident in Leader Responses?}

Mezirow's psychological approach to transformational learning seems to explain the responses of the leaders in this study. The transformational learning theory expanded to include organizational or group transformation, fostering transformation learning, and finally the ethical considerations of fostering a transformational learning experience. This expansion of transformational learning, according to Baumgartner (2001), "has expanded our understanding of adult learning by explicating the meaning-making process. It is not what we know but how we know that it is important (p. 22)". The elements of experience and critical reflection are especially evident in the responses of all three leaders. Central to the theory is a critical reflection because it allows the examination of underlying beliefs, assumptions, and values of the experience or problem (Merriam et al., 2007). According to Mezirow (1997), transformational learning takes place when the situation confronting the individual is unfamiliar, and already known strategies cannot be applied to resolve the situation. The responses of the leaders in the study revealed they learned from experience and indeed improved the way they lead.

Another element of transformational learning identified from the responses of the three leaders is development. Individual development, according to theories of learning, transformational learning is both inherent and an outcome of the process. In essence, the process of transformation is about change that is growth-enhancing and development (Merriam et al., 2007). All the leaders were seeking for the growth and development of individuals and their respective programs. According to Reardon et al. (2019), in critically reflective leadership, leaders continue to seek the development of the organization and the individuals within the organization. For instance, Leader L1 said that his goal as a leader is to make a difference in people's lives and assist them to realize their dreams. Si- 
milarly, Leader L3 and Leader L2 noted the growth in their respective programs and intend to continue on the growth path through new initiatives. The ability of these leaders to inspire to growth and development of not only their respective programs but individual employees within the departments reveals elements of transformation in their leadership (Bass, 1990). These leaders pay attention to the abilities and needs of individual employees in their department (Bass, 1990). "When leaders develop followers and allow them to gain experience is often a measure of success. Therefore, leaders who exhibit transformational learning behaviors have a direct influence on team member development, dedication, goal attainment, and indirect influence on overall performance" (Reardon et al., 2019: p. 29).

\subsection{Which Leadership Development Level Does Each Leader Reflect?}

Eigel and Kuhnert (2005), "defines Leadership Development Level (LDL) as the measurable capacity to understand ourselves, others, and our situations" (p. 359). Leaders at Development Level 2 (LDL) are characterized as having an overly simplistic view and concrete of the world, they think in terms of black-and-white, zero-sum, and win or loss. Leaders at LDL are not to see the perspectives of others. LDL 3 leaders have similar characteristics as LDL2 Leaders, however, LDL3 leaders are dependent on relationships to function, and therefore they find themselves in a pressing situation and cannot independently formulate a course of action. Also, their response to conflict is to get out it as soon as they can. Leaders reach LDL4 when they become independent of outside sources to make sense of self, others, and situations. At LDL4, leaders can make a separation between business "facts" and "feelings". However, LDL 4 leaders are limited by the inability to open up to different paradigms. Leaders at LDL 5, although rare, the defining characteristic is their ability to open up to others' paradigms. Thus, they can step away, take on a perspective, and objectively evaluate the paradigms that defined their understanding at earlier development levels.

A closer review of the three leaders' responses reveals that Leader L1, Leader L2, and Leader L3 are all at Leadership Development Level 4 (LDL 4). This is because all three leaders discussed the value of relationships in achieving group goals. However, they can take decisions without depending on the relationships established. They respond to conflicts or potential conflict by following laid down processes. In some cases, the leaders referred to adopting a participatory decision-making process to ensure that the majority of the employees feel part of the process. For instance, Leader L3 employs brainstorming at monthly meetings to generate ideas and make decisions on the next steps. Similar sentiments were expressed by Leader L1 and Leader L2 concerning opening up to other perspectives on issues and situations. Though the leaders do not give directives to those they work with, they have high expectations for them towards the realization of program goals. There is also a glimmer of LDL 5 in these leaders because in practice they welcome perspectives from others but at this point, it is not clear of 
any influence in their paradigm (e.g. Leader L3).

\subsection{Implications for Practice}

There are lessons to be learned from the findings of this study. Leaders need to know their strengths and weaknesses and identify team members with the requisite skills to complement the weakness (e.g. Leader L2 indicated giving assignments to team members who he believes have the requisite skills to accomplish a specific task). Furthermore, such a practice can contribute to a reduction in stress levels based on the experiences of the three leaders studied.

\subsection{Conclusion}

The findings of the research reveal that all three leaders incorporate elements of the adult learning theory/model in leadership practices. The models include andragogy, transformational learning, and experiential learning. It was evident from the research that prior experiences influence the development of these three individuals as leaders. For example, the leaders engage in critical reflection of their experiences, which informs future decisions and actions (Reardon et al., 2019). As noted by Kakabadse and Kakabadse (2009), leadership is a development process based on choices the leader makes. The study is significant because it is among few studies to explore the role of adult learning in leadership development, and extends further the conversation of the need for adult learning principles to be in cooperated in leadership development programs. In addition, the findings of the study underscore the critical role of prior experiences in the future decision-making by adult learners in leadership (Lapina, 2018).

\subsection{Limitations}

The current study has some limitations that future studies should address. First, the sample of three is small even for qualitative studies, so future studies may consider increasing the sample size. Second, the findings of the study are not generalizable because the study is limited to a specific context in higher education. Conducting similar studies with leaders in different sectors and cultural context is necessary to affirm the influence of adult learning principles in leadership practice.

\section{Conflicts of Interest}

The author declares no conflicts of interest regarding the publication of this paper.

\section{References}

Albert, J. F. (undated). Leaderly Learning: Understanding and Improving the Learning Capacity. Spokane, WA: Gonzaga University.

Allen, S. J. (2007). Adult Learning Theory and Leadership Development. Leadership Review, 7, 26-37.

http://citeseerx.ist.psu.edu/viewdoc/download?doi=10.1.1.455.8600\&rep=rep1\&type=pdf 
Argyris, C. (1991). Teaching Smart People How to Learn. Harvard Business Review, 3, 4-15. http://pds8.egloos.com/pds/200805/20/87/chris_argyris_learning.pdf

Arntzen, E. (2016). The Changing Role of Deans in Higher Education-From Leader to Manager. Universal Journal of Educational Research, 4, 2068-2075. https://doi.org/10.13189/ujer.2016.040918

Bass, B. M. (1990). From Transactional to Transformational Leadership: Learning to Share the Vision. Organizational Dynamics, 18, 19-31. https://doi.org/10.1016/0090-2616(90)90061-S

Baumgartner, L. M. (2001). An Update on Transformational Learning. In S. H. Merriam (Ed.), The New Update on Adult Learning Theory (pp. 15-24). San Francisco, CA: Jossey, Bass.

Bennis, W. (1984). The Four Competencies of Leadership. Training and Development Journal, 38, 14-19.

Bryman, A., \& Lilley, S. (2009). Leadership Researchers on Leadership in Higher Education. Leadership, 5, 331-346. https://doi.org/10.1177/1742715009337764

Cale, M. C. (2017). Learning While Leading: A Multiple Case of Principals' Ways of Knowing. Dissertation.

Curnow, C., Mulvaney, R., Calderon, R., Weingart, E., Nicely, K., Keller-Glaze, H., \& Fallesen, J. (2006). Advanced Learning Theories Applied to Leadership Development. Technical Report, Center for Army Leadership. https://doi.org/10.21236/ADA462784

Eigel, K. M., \& Kuhnert, K. W. (2005). Authentic Development: Leadership Development Level and Executive Effectiveness. In W. L. Gardner, B. J. Avolio, \& F. O. Walumbwa (Eds.), Authentic Leadership Theory and Practice (pp. 357-385). London: Elsevier.

Foote, L. S. (2015). Transformational Learning: Reflections of an Adult Learning Story. Adult Learning, 26, 84-86. https://doi.org/10.1177/1045159515573017

Freed, C. A. (2016). The Role of Emotional Intelligence in Community College Leadership. Dissertation.

Goleman, D. (2004). What Makes a Leader? Harvard Business Review, 82, 82-91. http://vnn1.online.fr/Cafeteria/Leadership/Harvard\%20Business\%20Revew\%20-\%20W hat\%20Makes\%20A\%20Leader.pdf

Hamidifar, F., \& Ebrahimi, M. (2016). Academic Leadership in a Private University: The Iranian Case Study. International Educational Studies, 9, 193. https://doi.org/10.5539/ies.v9n5p193

Hofmeyer, A., Sheingold, B. H., Klopper, C. H., \& Warland, J. (2015). Leadership in Learning and Teaching in Higher Education: Perspectives of Academics in Non-Formal Leadership Roles. Contemporary Issues in Education Research, 8, 181-192.

http://hsrc.himmelfarb.gwu.edu/son_nurs_facpubs/175 https://doi.org/10.19030/cier.v8i3.9348

Hoppe, M. H. (2007). Adult Development Theory May Boost Global Leadership. Issues and Observations, 27, 21-22. https://doi.org/10.1002/lia.1210

Johnson, J. R. (2002). Leading the Learning Organization: Portrait of Four Leaders. Leadership and Organization Development Journal, 23, 241-249. https://doi.org/10.1108/01437730210435956

Kakabadse, N. K., \& Kakabadse, A. (2009). A Dynamic Theory of Leadership Development. Leadership and Organization Journal, 30, 563-576. https://doi.org/10.1108/01437730910981935

Knowles, M. S. (1970). The Modern Practice of Adult Education: Andragogy versus Pedagogy. New York: New York Association Press. 
Knowles, M. S., Holton III, E. F., \& Swanson, R. A. (2005). The Adult Learner: The Definitive Classic in Adult Education and Human Resource Development (6th ed.). Butterworth-Heinemann: Elsevier. https://doi.org/10.4324/9780080481913

Kolb, D. A. (1984). Experiential Learning: Experience as the Source of Learning and Development. Englewood Cliffs, NJ: Prentice Hall.

Kouzes, J., \& Posner, B. (2006). The Leadership Challenge: How to Make Extraordinary Things Happen in an Organization (3rd ed.). San Francisco, CA: Jossey-Bass.

Lapina, A. (2018). Facilitating Coping through Reflective Learning in Adult Education. Adult Learning, 29, 131-140. https://doi.org/10.1177/1045159518776126

Madsen, W., O’Mullan, C., \& Keen-Dyer, H. (2014). Learning and Leadership: Evaluation of an Australian Rural Leadership Program. Australian Journal of Adult Learning, 54, 30-49. https://files.eric.ed.gov/fulltext/EJ1031003.pdf

Merriam, S. B., Caffarella, R. S., \& Baumgartner, L. M. (2007). Learning in Adulthood: A Comprehensive Guide (3rd ed., pp. 83-104, 130-158). San Francisco, CA: Jossey-Bass.

Merriam, S. H. (2001). Andragogy and Self-Directed Learning Pillars of Adult Learning Theory. The New Update on Adult Learning Theory, 2001, 3-14. https://doi.org/10.1002/ace.3

Mertler, C. A. (2019). Action Research: Improving Schools and Empowering Educators (6th ed.). Los Angeles, CA: SAGE.

Mezirow, J. (1997). Transformative Learning: Theory to Practice. New Directions for Adult \& Continuing Education, 74, 5-12. https://doi.org/10.1002/ace.7401

Middlehurst, R., Goreham, H., \& Woodfiled, S. (2009). Why Research Leadership in Higher Education? Exploring Contributions from the UK's Leadership Foundation for Higher Education. Leadership, 5, 311-329. https://doi.org/10.1177/1742715009337763

Morris, L. E., \& Klunk, C. D. (2016). Revisiting Adult Development: Changing Perspectives, Capabilities, and Worldviews. Adult Learning, 27, 3-6. https://doi.org/10.1177/1045159515616239

Reardon, R., Fite, K., Boone, M., \& Sullivan, S. (2019). Critically Reflective Leadership: Defining Successful Growth. International Journal of the Whole Child, 4, 20-32. https://digital.library.txstate.edu/handle/10877/9074

Sahgal, P., \& Pathak, A. (2007). Transformational Leaders: Their Socialization, Self-Concept, and Shaping Experiences. International Journal of Leadership Studies, 2, 264-278. https://www.regent.edu/acad/global/publications/ijls/new/vol2iss3/sahgal/SahgalPatha k_Vol2Iss3.pdf

Scott, G., Coates, H., \& Anderson, M. (2008). Learning Leaders in Times of Change: Academic Leadership Capabilities for Australia Higher Education. Strawberry Hills: The Carrick Institution of Learning and Teaching in Higher Education.

Senge, P. M. (1990). The Fifth Discipline: The Art and Practice of the Learning Organization. New York: Doubleday/Currency.

Sharma, S. (2013). Exploring American History X through Transformational Learning. New Horizons in Adult Education and Human Resource Development, 25, 24-35. https://doi.org/10.1002/nha.20005

Stevens, J. (2014). Perceptions, Attitudes \& Preferences of Adult Learners in Higher Education: A National Survey. Journal of Learning in Higher Education, 10, 65-78. https://files.eric.ed.gov/fulltext/EJ1143318.pdf

Van Velsor, E., \& Guthrie, V. A. (1998). Enhancing the Ability to Learn from Experience. In C. D. McCauley, R. S. Moxley, \& E. Van Velsor (Eds.), The Center for Creative Leadership Handbook of Leadership Development (pp. 242-261). San Francisco, CA: Jos- 
sey-Bass.

Vilkinas, T. (2014). Leadership Provided by Non-Academic Middle-Level Managers in the Australian Higher Education Sector: The Enablers. Tertiary Education and Management, 20, 320-338. https://doi.org/10.1080/13583883.2014.966141

Wuestewald, T. (2016). Adult Learning in Executive Development Programs. Adult Learning, 27, 68-74. https://doi.org/10.1177/1045159515602256 